\title{
Suicidal Thoughts
}

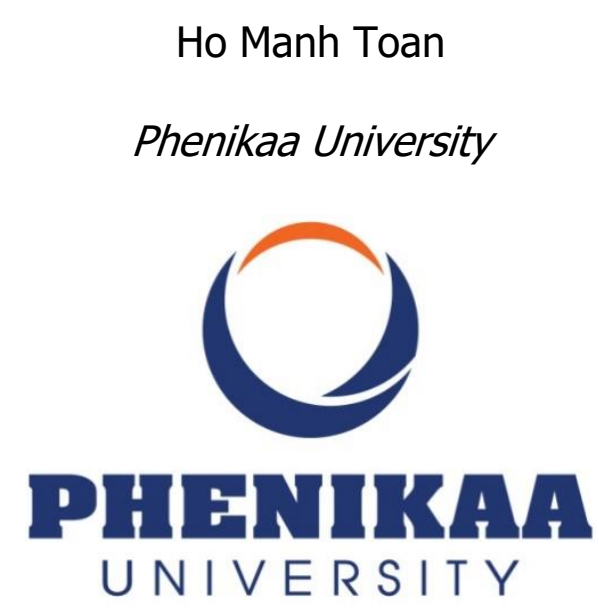

February 14, 2021

"I swear to God I want to just slit my wrists and end this bullshit Throw the Magnum to my head, threaten to pull shit ( $N *$, what the fuck?) And squeeze until the bed's completely red (It's too late for this shit, man) I'm glad I'm dead, a worthless fuckin' buddha head The stress is buildin' up, I can't-I can't believe (Yo, I'm on my way over there, man) Suicide's on my fuckin' mind, I wanna leave I swear to God I feel like death is fuckin' callin' me But nah, you wouldn't understand ( $N^{*}$, talk to me please, man!)"

_ The Notorious B.I.G. [1] _

It is no coincidence that Albert Camus once asserted that the truly serious philosophical problem is suicide [2]. Scientists have put tremendous effort into understanding what is going on inside our brains. Surely, why a person decided to end his/her own life is a serious matter. Once again, echoing Camus: "Judging whether life is or is not worth living amounts to answering the fundamental question of philosophy" [2]. 
Suicide is a tragic and personal issue. Despite the honesty of statistical models or theoretical framework, science certainly feels distant and too objective for a person who has been through such a dark cycle. This feeling is no stranger to top experts in the field. Robert A. Burton, a renowned neurologist, suggested that even with good theories, being so confident with our ability to predict or even read someone's mind is naïve [3].

When Deanna Csomo McCool wrote: "After ending the phone call, I crumpled into a heap and screamed" [4], I felt the brokenness inside her word, and I, too, scream with her. Thus, that is why arts, fictions, or films are what we come to when we experience such dark moments.

However, the reality remains. Around 800,000 people die every year because of suicide, and for young people, suicide is one of the primary causes of death [5]. In the age of social media, the young population has to face the risk of depression and suicide in a greater deal than before [6]. So, even though arts help us through our dark times, good science is still a prominent option in leading us toward a better future [7].

Theoretically, the Interpersonal Theory of Suicide [8] and Integrated Motivational-Volitional Model [9] are leading schools of thought in explaining the mechanism in suicidal ideation. However, the generalizability of these theories may hold up to scrutiny when dealing with the unpredictability of the issue. Moreover, labeling the complexity of suicidal ideation to a limited number of factors leads to the inflexibility of building a statistical investigation model. Currently, the conventional frequentist approach also seems unfit to deal with the complexity of social data. The sensitive nature of suicide may also result in a low number of observations.

Here, we need a dynamic model to help explain the complexity of suicidal ideation. The explanation needs to consider both what is going on inside a person's mind, as well as the outside influence, such as culture or incoming information. The mindsponge mechanism $[10,11]$, which was initially proposed to understand how a person deals with new cultural values, can be a viable option for psychologists. Regarding the problems with data, Bayesian statistics, with its ability to update belief as well as the feasibility in dealing with a low number of observations [12-14], can help to understand the issue.

The suggested approaches are only one of many viable ways. The complexity of suicide indeed requires many approaches. It can be philosophy, psychology, or sociology. However, it should be humble and aim to achieve a clear goal: helping people. 
"When I die, f*ck it, I wanna go to hell 'Cause I'm a piece of shit, it ain't hard to fuckin' tell." _ The Notorious B.I.G. [1] _

\section{References}

[1] The Notorious B.I.G. (1994). Suicidal Thoughts [Recorded by The Notorious B.I.G.]. On Ready to Die. Bad Boy Records.

[2] Camus, A. (1942). The myth of Sisyphus. Penguin UK.

[3] Burton, R. A. (2018). The theory of mind myth. Aeon. Retrieved from https://aeon.co/essays/think-you-can-tell-what-others-are-thinking-think-again

[4] McCool, D. C. (2019). Total eclipse. Aeon. Retrieved from https://aeon.co/essays/when-a-childs-mental-health-diagnosis-comes-too-lateto-help

[5] Ritchie, H., Roser, M., \& Ortiz-Ospina. (2015). Suicide. Our World in Data. Retrieved from: https://ourworldindata.org/suicide

[6] Moreno, M. (2015). Status: suicidal. Aeon. Retrieved from https://aeon.co/essays/ifsuicide-is-signalled-on-social-media-should-you-intervene

[7] Sacks, O. (2019). The machine stops. The New Yorker. Retrieved from https://www. newyorker.com/magazine/2019/02/11/the-machine-stops

[8] Van Orden, K. A., et al. (2010). The interpersonal theory of suicide. Psychological Review, 117(2), 575.

[9] O'Connor, R. C., \& Kirtley, O. J. (2018). The integrated motivational-volitional model of suicidal behaviour. Philosophical Transactions of the Royal Society B: Biological Sciences, 373(1754), 20170268.

[10] Vuong, Q. H., \& Napier, N. K. (2015). Acculturation and global mindsponge: an emerging market perspective. International Journal of Intercultural Relations, 49, 354-367.

[11] Vuong, Q. H. (2016). Global mindset as the integration of emerging socio-cultural values through mindsponge processes: A transition economy perspective. In: J. 
Kuada (ed.) Global Mindsets: Exploration and Perspectives (pp. 109-126). London: Routledge.

[12] La, V. P., \& Vuong, Q. H. (2019). bayesvl: Visually learning the graphical structure of Bayesian networks and performing MCMC with 'Stan'. The Comprehensive $R$ Archive Network. Available from: https://cran.r-project.org/package=bayesvl.

[13] Vuong, Q. H., Ho, T. M., La, V. P. (2019). 'Stargazing' and p-hacking behaviours in social sciences: some insights from a developing country. European Science Editing, 45(2), 56-57.

[14] Ho, M. T., \& Vuong, Q. H. (2019). The values and challenges of 'openness' in addressing the reproducibility crisis and regaining public trust in social sciences and humanities. European Science Editing, 45(1), 14-17. 